\title{
Correction to: Detecting differentially methylated regions using a fast wavelet-based approach to functional association analysis
}

William R. P. Denault ${ }^{1,2,3^{*}}$ (D) and Astanand Jugessur ${ }^{1,2,3}$

The original article
can be found online
at https://doi.org/
$10.1186 / s 1285$
$9-021-03979-y$.
"Correspondence:
william.denault@
fhi.no
${ }^{1}$ Department
of Genetics
and Bioinformatics,
Norwegian Institute
of Public Health, Oslo,
Norway
Full list of author
information is
available at the end of
the article

the article

\section{Correction to:BMC Bioinformatics(2021) 22:61 https://doi.org/10.1186/s12859-021-03979-y}

Following publication of the original article [1], the authors identified an error in Table 1. The correct Table 1 is given below.

The author group has been updated above and the original article [1] has been corrected.

Table 1 Estimated type I error for different sample sizes and test functions

\begin{tabular}{|c|c|c|c|c|c|}
\hline \multirow[t]{2}{*}{ Test function } & \multirow[t]{2}{*}{$n$} & \multicolumn{4}{|l|}{$\alpha$ level } \\
\hline & & 0.5000 & 0.0100 & 0.0010 & 0.0001 \\
\hline Block & 100 & 0.49980 & 0.00992 & 0.00111 & 0.00017 \\
\hline Block & 500 & 0.50048 & 0.00978 & 0.00105 & 0.00009 \\
\hline Block & 1000 & 0.49950 & 0.01028 & 0.00090 & 0.00014 \\
\hline Bump & 100 & 0.50040 & 0.01026 & 0.00111 & 0.00004 \\
\hline Bump & 500 & 0.50182 & 0.01040 & 0.00080 & 0.00009 \\
\hline Bump & 1000 & 0.50050 & 0.00961 & 0.00098 & 0.00008 \\
\hline HeaviSine & 100 & 0.50007 & 0.00982 & 0.00085 & 0.00009 \\
\hline HeaviSine & 500 & 0.49956 & 0.00975 & 0.00091 & 0.00007 \\
\hline HeaviSine & 1000 & 0.49965 & 0.01026 & 0.00103 & 0.00009 \\
\hline Doppler & 100 & 0.50054 & 0.01014 & 0.00097 & 0.00009 \\
\hline Doppler & 500 & 0.50089 & 0.01007 & 0.00100 & 0.00008 \\
\hline Doppler & 1000 & 0.49916 & 0.01037 & 0.00095 & 0.00013 \\
\hline
\end{tabular}




\section{Author details}

${ }^{1}$ Department of Genetics and Bioinformatics, Norwegian Institute of Public Health, Oslo, Norway. ${ }^{2}$ Centre for Fertility and Health, Norwegian Institute of Public Health, Oslo, Norway. ${ }^{3}$ Department of Global Public Health and Primary Care, University of Bergen, Bergen, Norway.

Published online: 26 May 2021

\section{Reference}

1. Denault WRP, Jugessur A. Detecting differentially methylated regions using a fast wavelet-based approach to functional association analysis. BMC Bioinform. 2021;22:61. https://doi.org/10.1186/s12859-021-03979-y.

\section{Publisher's Note}

Springer Nature remains neutral with regard to jurisdictional claims in published maps and institutional affiliations. 